\title{
ESPAÇOS E CULTURAS DE FRONTEIRA NA AMAZÔNIA OCIDENTAL $^{1}$
}

\author{
ESPACIOS E CULTURAS DE FRONTERA EN LA AMAZONÍA \\ OCCIDENTAL
}

\section{SPACES AND BOUNDARIES CULTURE FROM THE SOUTHERN AMAZON}

\author{
Laís M. Cardia \\ Universidade Federal do Acre \\ Doutora em Antropologia Social. \\ Diretora do Núcleo de Pesquisa sobre Migração, \\ Identidade e Memória - NUPIM/UFAC/CNPq. \\ Av. Bem Te Vi, 339/172 - Indianópolis - SP \\ 04524-030 - São Paulo \\ E-mail: lmcardia@uol.com.br
}

\begin{abstract}
Resumo
Desenvolver investigações em áreas de fronteira impõe grandes desafios pela complexidade que se apresenta considerando a multiculturalidade e a multiplicidade étnicas ali existentes. Este artigo é resultado de investigações realizadas entre 2006 e 2008 na fronteira Brasil (Assis Brasil-Acre), Peru (Iñapari-Madre de Dios) e Bolívia (Bolpebra-Pando). Pretendo discutir aspectos concatenados entre transformação do espaço, culturas de fronteira e diversidades culturais, fenômenos presentes entre essas populações, resultantes de uma convivência cotidiana duradoura. Apesar da divulgação da "integração" entre as populações da Tríplice Fronteira estar nos discursos regionais, locais e nacionais, os moradores das três localidades já vivem, de fato, fluxos e vínculos que ultrapassam as fronteiras nacionais.
\end{abstract}

Palavras-chave: Amazônia Ocidental, culturas de fronteira, transformação do espaço.

\footnotetext{
${ }^{1}$ A primeira parte desta investigação, em 2006, foi realizada com recursos do $\mathrm{CNPq} / \mathrm{Brasil}$ e coordenação conjunta com o Dr. José Ma. Valcuende Del Río. Em 2007 e 2008 sua continuidade contou com o apoio total da Agencia Española de Cooperación Internacional para o Desenvolvimento - AECID e com a coordenação do Dr. Valcuende. O Projeto foi concluído no início de 2009 e teve como resultado a publicação de dois livros, sendo um em espanhol e o outro uma versão em português.
} 


\title{
Resumen
}

Investigar em contextos fronterizos implica un gran desafío por la complejidad que presenta uma realidad multicultural, en la que habitualmente están presentes diversos grupos étnicos. En este artículo, resultado de la investigación desarrollada entre los años 2006 y 2008 en la Triple Frontera Brasil, Perú y Bolívia, pretendo discutir la articulación entre transformación del espacio, culturas de frontera y diversidad cultural, fenómenos presentes en unas poblaciones que han mantenido uma convivencia cotidiana duradera. A pesar de que la idea de "integración" hace poco está presente en los discursos regionales, locales y nacionales, los habitantes de las tres localidades ya viven, de hecho, flujos y vínculos que sobrepasan las fronteras nacionales.

Palbras clave: Amazonia Occidental, culturas de frontera, transformación del espacio.

\begin{abstract}
To perform investigations whiting boundary areas, major challenges are imposes due to the complexity which is present whenever it is considered the existing ethnical multiculturalism and multiplicity in that places. This article is the outcome from investigations performed between 2006 and 2008 in the Brazilian frontier (Assis BrazilAcre), Peru (Iñapari-Madre de Díos) and Bolivia (Bolpebra-Pando). It intends to discuss the correlated cultural aspects between the changes in the space, boundary cultures, and cultural diversities, phenomena which are present in those populations, and which result from a daily and constant acquaintanceship. Despite the propagation of the "integration" between populations of the Triple Frontier is part of the regional, local, and national speeches, those who live there in fact, already live the flows and links that surpass national frontiers.
\end{abstract}

Key-words: Southern Amazon, culture from the, changes in the space.

\section{Introdução}

A antropologia contribui de forma definitiva para um novo olhar sobre a relação entre culturas de fronteira, diversidade cultural e a noção de pertença. As diversidades culturais e étnicas existentes na tríplice fronteira da Amazônia Ocidental - Acre (Assis Brasil, Brasil), Pando (Bolpebra, Bolívia) e Madre de Dios (Iñapari, Peru) (ver mapa abaixo) sugerem uma nova e peculiar articulação dos espaços no cotidiano de seus moradores, a partir da nova maneira de entender as relações que se estabelecem entre essas populações. Entretanto, os conflitos estão presentes, assim como os mecanismos para superá-los. São esses os eixos que justificam a discussão dessas formas de articulação da dinâmica espacial, fronteiriça e cultural nas localidades mencionadas. $\mathrm{O}$ objetivo é analisar como se dá o reconhecimento dos "outros", diferentes em seus modos de viver, em suas culturas e, ao mesmo tempo, como são (re)criadas as culturas 
de fronteira, considerando as (re)valorizações de espaços na fronteira. Nessa perspectiva, e considerando que essas populações vivem, de fato, um longo processo de “integração", a hipótese a ser demonstrada é que, apesar das diversidades e dos conflitos presentes, os habitantes da fronteira interagem cotidianamente em certa sintonia, sem abandonar as particularidades próprias de cada cultura praticamente ignorando as dimensões político-administrativas, na tentativa de demarcar seus espaços e lugares, em um território compartilhado.

Velhos temas em novas ordens são precisamente os casos de estudos de cultura e diversidade cultural que os antropólogos exploram, agora também sob a ótica das integrações transnacionais e das cidades, por exemplo. A investigação antropológica adota metodologias que suponham a adaptação da prática etnográfica "multisituada" ou "multi-local", de maior duração. Essa prática define seus objetos de estudo por meio de várias técnicas que consistem em seguir o movimento e traçar a relação entre diversos aspectos desses fenômenos: histórias de vida, entrevistas semi-estruturadas e observação participante, fazem parte dessas técnicas.

Por se tratar de fenômenos que envolvem relações interétnicas e multiculturais que necessitam e serão aprofundados, as informações não têm o caráter de resultados finais, mas algumas considerações que já são possíveis visualizar nessa região. Assim, aproximamos-nos de um universo de investigação em que convivem diversas lógicas, diversos grupos articulados em torno das diferenças geradas pelas fronteiras internacionais. São grupos de pessoas que aprenderam a instrumentalizar de forma diversa, uma demarcação político-administrativa, as "culturas de fronteiras". Em um mesmo espaço convergem tradições, saberes, formas singulares de apropriar-se do meio, que têm como condicionante fundamental a fronteira. 


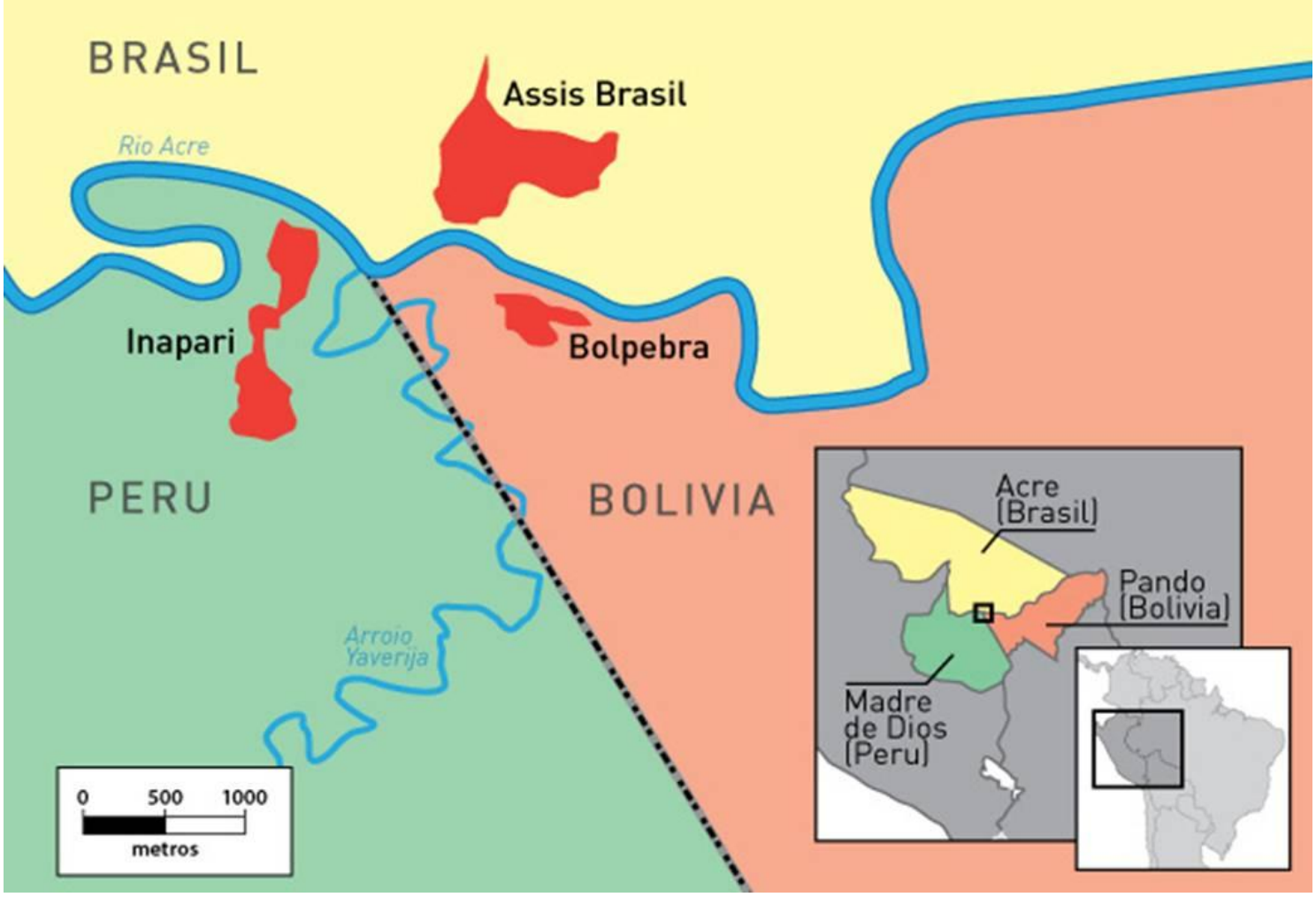

\section{Espaço e "culturas de fronteira"}

O universo trabalhado encerra em si uma dimensão paradoxal: por um lado localiza-se num território (físico e cultural) determinado onde convivem os "lugares" e "não lugares" em função dos grupos sociais aos quais fazemos referência. Para os habitantes que vivem neste espaço durante gerações, a fronteira é um "lugar", "seu lugar", aonde vêm construindo espaços de relações sociais, vinculações afetivas e emocionais, formas concretas de entender as relações com o meio. Para uma boa parte da sociedade brasileira, e provavelmente das sociedades peruana e boliviana, a fronteira é um "não lugar": espaço de passagem, liminar, intermediário, derrapante, poroso, um simples lugar de passagem. Para os novos habitantes que chegaram a esta zona, deslocados desde as serras peruanas, desde o sul da Bolívia e de diversas regiões do Brasil, o "não lugar" vai adquirindo novas formas e significados, que se traduzem também em outras formas de entender as relações humanas e as relações com o meio que convivem e, às vezes, se confrontam com os grupos já assentados ali.

As noções teóricas aqui contidas envolvem a discussão do espaço, culturas de fronteira e diversidades culturais, resultantes de uma relação culturalmente vivida tanto 
entre os grupos humanos entre si, como entre estes e o meio. Uma trama socioambiental interdependente, um sistema que integra significados, sentimentos, trajetórias. Compartilhando com um dos pensamentos de Augé (1993), pode-se dizer que as formas de organizar espaços e constituir lugares, dentro de um grupo social são uma, das inúmeras práticas, que esse mesmo grupo dispõe para reforçar seus componentes identitários, em relação a outros grupos sociais.

Quando se fala de espaço e de lugar, não ficam muito claros os seus limites. Como observam Machado (1996), Valcuende Del Rio (1998) e Valva (2001), o que começa como espaço indiferenciado transforma-se em lugar na medida em que o conhecemos melhor e o dotamos de valor, associado a uma dimensão simbólica. A fronteira, como idéia abstrata é próxima aos habitantes de qualquer estado, que precisam exatamente do limite para ser diferentes dos "outros" e para buscar vínculos de interação entre um "nós" definido politicamente. A fronteira, como espaço concreto se apresenta como um âmbito longínquo, hostil. É o espaço por colonizar, por domesticar. É o espaço deslocado dos imigrantes.

Neste sentido, partimos da necessidade de confrontar todas essas lógicas contraditórias, observando ao mesmo tempo, as diferentes dinâmicas que convergem nesses lugares de fronteira, física e cultural. Por um lado, das dinâmicas dos grupos que um dia foram deslocados, porém que hoje encontram seu lugar na fronteira, por outro as dinâmicas dos novos grupos desterritorializados, os grupos de (i)migrantes e as minorias étnicas, reagrupados nas novas localizações, que reconstituem a sua história e definem processos de integração e de resistência por vezes organizada, outras anárquicas, tornada visível e sublinhada pelo processo de estigmatização dessa população. Porém, se estamos atentos às dinâmicas internas das próprias populações, não podemos esquecer a significação destes espaços.

A idéia de que a fronteira tem sido só um espaço para a separação das populações fronteiriças, faz tempo foi descartada. A fronteira como sistema acaba por gerar relações que necessitam precisamente desta linha política para subsistir. A tal ponto isto é assim que alguns autores falam de "cultura de fronteira" (Uriarte: 1994). Sem dúvida, é perigoso territorializar a cultura. Seria o mesmo que personalizar a fronteira. A fronteira não tem cultura, idependemente que de gere elementos compartilhados em uns e outros lugares fronteiriços. Neste sentido, seria mais 
apropriado falar de "culturas de fronteira" (Valcuende, 1998), de grupos que, a partir de suas próprias posições aprenderam a instrumentalizar, de forma diversa, esta demarcação político-administrativa. Um espaço polifônico, com dinâmicas culturais diferentes.

Em um mesmo espaço convergem tradições, saberes, formas singulares de apropriar-se do meio que têm um condicionante fundamental a fronteira. $\mathrm{O}$ condicionante é similar em distintos contextos, porém ao mesmo tempo, é singular em função das características dos grupos sociais que interatuam na mesma porque os grupos humanos respondem de formas diversas perante os mesmos fatos.

Da perspectiva das culturas de fronteiras, que pretende escapar de uma visão mecanicista e reificadora da cultura, abrem-se oportunidades para uma verificação da possibilidade de ocupação econômica com preservação de ecossistemas, bem como se o plano de uso da terra, que inclui empreendimentos econômicos, contempla garantias de conservação ambiental. (Barbosa, 2003). Esses aspectos, uma vez levados em conta, ressaltam que a floresta desempenha funções vitais para a manutenção das condições ecológicas da produção agropecuárias, por exemplo, além de constituir uma fonte de subsistência para populações indígenas ${ }^{2}$ e não indígenas.

Quais os grupos e como definem a significação dos espaços urbanos? Como podem conviver estes grupos a partir de lógicas às vezes contraditórias? Quais são as consequências da chegada de uma nova população desvinculada com o meio? Estas são algumas perguntas que têm a ver com a manutenção ou a modificação das culturas de fronteira, porém também estão diretamente relacionadas com a significação e manutenção do próprio meio. Devemos também ter em conta que os problemas ambientais são fundamentalmente problemas sociais, e que não é possível realizar uma abordagem correta do meio sem considerar os interesses dos grupos que interatuam com o mesmo.

A centralidade que adquire na atualidade este espaço periférico da Amazônia passa, curiosamente, por vincular essa região e outras na Colômbia e no Equador a partir de novos projetos de rodovias, por exemplo (Valcuende, 1999), aos novos centros

\footnotetext{
${ }^{2}$ É importante esclarecer que trabalhamos com famílias indígenas (Jaminawa e Manchineri) que se encontram no espaço urbano, uma vez que não tínhamos autorização oficial para entrada em área indígena.
} 
de produção brasileiros que encontraram na expansão da soja uma nova forma de acrescentar valor a um espaço que continua sendo considerado marginal.

Do nosso ponto de vista, as vinculações culturais desta zona atualmente (no passado é mais que possível que existissem) se produzem a partir da economia extrativista, que superou os limites demarcados pelos distintos Estados, assentando uma nova população com suas próprias singularidades. A resistência que produziu novas formas de exploração, trazidas pelos colonos sulistas, no caso do Brasil, ou pelos serranos, no caso de Madre de Dios no Peru, exprimem a sua importância, tanto que se traduziu em mecanismos de resistência social, inclusive perante os novos habitantes brasileiros ou peruanos. Os amazônidas da fronteira encontraram precisamente suas singularidades em uma atividade que se vinculou a uma ampla zona peruana, brasileira e boliviana: a atividade extrativista e o sistema socioeconômico e cultural que o gerou acrescentando valor à floresta, um espaço desprezado por outros grupos, que consideraram e, em alguns casos consideram, que devia e deve ser destruída. Esta visão se traduz através da amplitude dos desmatamentos e das queimadas na Amazônia. A implantação da rodovia que interliga o Brasil ao Oceano Pacífico, via Estado do Acre/Peru vem produzindo modificações das paisagens, cujos impactos ambientais podem se refletir para a poluição do ar atmosférico, erosão do solo e perda da biodiversidade, quando se observam as pressões sobre os recursos madeireiros da floresta tropical Amazônica nos países envolvidos (Barbosa, 2003).

O espaço, um conceito polissêmico, e lugar deveriam diferenciar-se do conceito de território. No entanto, alguns autores afirmam que a noção de território deve juntarse a elas porque está associada à idéia de realidade social (Garcia, 1976). Para Valcuende o território é o lugar onde interagem indivíduos

\footnotetext{
“(...) un marco fundamental de referencia para adscribir y autoadscribir (identificar) individuos y grupos. Su vinculación con un espacio determinado es uno dos elementos centrales tanto en la configuración de la identidad individual, como en los procesos de identificaciones colectivas. La organización sociopolítica del territorio define, en buena medida, las características que se presuponen a los individuos que comparten un espacio y un tiempo concretos" (1998:70).
}

De forma geral a antropologia, hoje, procura discutir a definição de território e territorialização, vinculada à construção do espaço e de lugares sociais e identidades individuais e coletivas, onde histórias são compartilhadas e memórias são ativadas. 
O mesmo autor explora a construção social do território e a definição de seus limites como aspectos constitutivos das formas como sujeitos sociais constroem seus próprios territórios. Eles são marcos territoriais com característica sócio-econômicas singulares, a partir dos quais os grupos sociais reafirmam ou negam simbolicamente suas fronteiras, aquelas definidas pelo Estado, e aquelas definidas a partir da interação social.

As fronteiras constituem marcos simbólicos. Entretanto, esses marcos são, sobretudo, de referências mentais que guiam a percepção da realidade, produtos de uma capacidade mágica de representar o mundo por um mundo paralelo de sinais, por meio do quais os homens percebem e qualificam a si próprios, ao corpo social, ao espaço e ao próprio tempo: o imaginário, um sistema simbólico de representações coletivas que atribui significado ao real e que pauta os valores e as condutas. As fronteiras são, sobretudo culturais, construções de sentido, fazendo parte do jogo de representações que estabelece classificações, hierarquias e limites, guiando o olhar e a apreciação sobre o mundo.

Se considerarmos correta essa afirmação, também é certo que as fronteiras não são somente representações. Os limites jurídicos ou sociais impõem identificações, normas, regras diferenciais em função do lado de lá da fronteira em que o grupo social está situado, ou em que um grupo social se situa, realidades que nem sempre são coincidentes. Hoje há, sem dúvida, uma tendência para se pensar as fronteiras a partir de uma concepção que se ancora na territorialidade e se desdobra no político. Constituemse na delimitação de um território que aponta sentidos socializados de reconhecimento. Mesmo na dimensão da territorialidade e do político, discutida também por Escalera (1999) e por Valcuende (1999), o conceito de fronteira tem avançado para os domínios de uma construção simbólica de pertencimento - a identidade - e que corresponde a um marco de referência imaginária que se define pela unidade e pela diferença. Assim, o conceito de fronteira aponta, necessariamente, para princípios de reconhecimento que envolvem analogias, oposições e correspondências de igualdade e diferença, em um jogo permanente de interpretações e conexões variadas.

Nesse sentido, ao definir limites e traçar fronteiras, operar aspectos inclusivoexclusivos a ao permitir a identificação dos que nele estão inscritos, o território surge como um elemento articulador e diferenciador porque a condição de fronteira é dada 
pela situação de ser borda, margem, franja. Admitir tal condição é postular uma condição de estranhamento, que possibilita o que se convencionou chamar como sendo a melhor atitude antropológica: ver "mais longe" (Pesavento, 2003).

Assim, o que dá a um lugar sua especificidade é o fato de que a fronteira se constrói a partir de uma constelação particular de relações sociais, que se encontram e entrelaçam num locus particular, tornando-se um ponto único, na intersecção dessas relações. Trata-se de um lugar de encontro. Portanto, em vez de se pensar o espaço, o território e o lugar como áreas com fronteiras ao redor, pode-se imaginá-los como momentos articulados em redes de relações, experiências e entendimentos sociais que vão sendo construídas em numa escala muito maior que permite um sentido do lugar, que inclui uma consciência de suas ligações com o mundo, que integra o global e o local (Cardia, 2004). São os marcos simbólicos que permeiam o cotidiano de grupos sociais em interação.

Os estudos da antropologia e outras áreas do conhecimento (sociologia, história, geografia) têm contribuído muito com as discussões acerca da territorialidade, do espaço, do lugar, da cidade, do tempo e dos respectivos sujeitos sociais que compõem esse universo, principalmente estudos onde várias vozes se articulam (a polifonia da fronteira) buscando dar visibilidade a esses mesmos sujeitos sociais (Cardia, 2004).

Pode-se afirmar que o espaço, o território e o lugar como fenômenos culturalmente constituídos, delimitam fronteiras culturais e fazem parte das identidades de comunidades e, como tal, proporcionam o reconhecimento de uma alteridade, bem como de uma integração progressiva dessa alteridade. Sujeitos sociais, embora reconhecendo a sua pertença a lugares distintos, têm o lugar do "outro" como referência valorizada. O jogo entre o "aqui" e o "além" articula a relação do "outro" e marca a clivagem que organiza as identidades inclusiva e exclusiva. As noções de espaço, território e lugar são, portanto, significativas para se pensar a noção de pertença e o espaço de referência de determinados grupos culturais, étnicos, sociais, políticos. Quando se trata de estudar grupos de pessoas com características culturais e étnicas diferenciadas, como é o nosso caso, não se pode deixar de vincular às noções acima apontadas com as discussões sobre identidades social, cultural e étnica.

Barth (1976) entendeu a identidade a partir da noção de "grupos de relação", ou seja, uma forma de organização social, em populações cujos membros se identifiquem e 
são identificados como tal. Apoiado na literatura antropológica que valorizava a cultura enquanto um dos elementos definidores da etnicidade, Barth criticou uma visão de cultura como isolada e insistiu na característica da auto-definição ou da atribuição do outro. Assim, é a "fronteira" que define o grupo e não o material cultural como imaginavam os culturalistas. A "fronteira" é criada por uma vontade de se diferenciar e, também, alguns elementos culturais, que marcam uma identidade específica (Cuche, 1999). A concepção de identidade de Barth é mais dinâmica porque atenta à circularidade cultural e à lógica de sua manipulação e ressignificação.

A noção de fronteiras culturais também elaboradas por Barth (1976), é acionada no processo de identificação para marcar os limites entre "eles" e "nós", estabelecendo, assim, a "fronteira simbólica". O que cria, ou demarca, os limites (espaços, territórios e lugares) é, também, a possibilidade/necessidade de um grupo de se diferenciar, de resgatar elementos culturais como marcadores de sua identidade específica. Embora admitindo que a relação espaço/sociedade não seja a única a integrar a dinâmica da constituição das identidades. Paul-Lévy e Segaud privilegiaram um viés de análise que incorpora o espaço na definição de identidades, apoiadas numa formulação de que de algum modo legitimou o campo disciplinar da antropologia do espaço: “A relação para com o espaço é, por assim dizer, uma garantia universal das particularidades das identidades" (1983:30).

\section{Fronteiras, territorialização e referentes de identificação}

Com estes referenciais nos aproximamos de uma realidade fronteiriça concreta, onde convivem diferentes grupos que se autodefinem e são definidos em relação às realidades sócio-políticas diferenciadas. Um mesmo espaço, nesse caso fronteiriço, é territorializado de forma diversa, em função de diferentes normas políticas, referentes culturais, formas de entender e apropriar-se do meio por parte dos diferentes grupos sociais, realidades sócio-políticas diferenciadas.

A modificação do espaço, neste caso, planejada a partir dos centros de decisão política, é um fator fundamental que nos leva a alguns desafios teóricos. O primeiro deles é comprovar a incidência de uma ação externa às sociedades locais nos processos de territorialização destes grupos. As posições de antropólogos como Godelier (1984), 
Palsson e Descola (2001), podem ser especialmente úteis neste sentido, já que vinculam as representações e práticas sociais com as características ambientais. Afinal, quando falamos de transformações socioeconômicas, em última instância nos referimos a mudanças em um meio onde se refletem de forma necessária as contradições dos sistemas humanos, que formam uma parte indissociável o sistema ambiental onde se encontram.

Ao iniciar as investigações, pretendíamos nos aproximar das distintas formas de territorialização de um mesmo espaço por parte de diferentes atores sociais, que precisavam conviver com as diferenças marcadas por uma fronteira políticoadministrativa. Uma realidade que se caracteriza pelas constantes mudanças e que agora vive um fato, que forma parte de um processo mais global e que pode afetar notavelmente as relações destas populações fronteiriças: a construção da Rodovia Transoceânica. Portanto, é fundamental analisar como é vivenciado esse processo por parte das populações locais diretamente afetadas pela execução do projeto, contrapondo-o aos discursos oficiais, que incidem em questões como o desenvolvimento - que é considerado prioritário por estas populações fronteiriças, supostamente "sustentáveis", e a integração - vivida paradoxalmente como um processo de desintegração, de acordo com a visão de uma boa parte dos habitantes da região.

O Acre e uma parte do Peru e Bolívia diante da presença efetiva do Estado foram se articulando, de certa forma, em função da economia baseada na seringa. A nova demarcação modifica algumas das linhas fronteiriças como área de interação. Habitualmente nos estudos sobre fronteiras tem-se diferenciado "limites" e "boundary". O limite é entendido como uma linha claramente demarcada e "boundary" faz referência a uma zona em que os limites são difusos diante das interações entre as populações onde são mais que habituais (Herrero, 1994). Nas zonas fronteiriças é habitual a coexistência do limite com o "boundary", ou seja, a existência de áreas de fronteira que se estruturam precisamente a partir de uma linha em função da qual se definem distintas moedas, tempo, preços, direitos, etc. As diferenças geradas pela linha de demarcação acabam por constituir uma parte de um sistema em que é preciso gerar redes de interação econômica, social e política, sobretudo quando a presença do Estado tenha sido pouco efetiva, assim como acontecem no caso da fronteira analisada. 
As áreas de fronteira podem se caracterizar pela intensa relação transfronteiriça entre populações, sobretudo quando falamos de fronteiras periféricas, de escasso valor estratégico, em que novos projetos agregam valor em um espaço considerado secundário.

Não podemos entender a significação desse espaço fronteiriço sem analisar o caráter marginal que vem ocupando no interior dos seus próprios Estados. Falamos de áreas periféricas dentro de divisões administrativas também periféricas. Não é estranho que essa região de "sobreviventes" tenha sido obrigada a gerar um sistema socioeconômico que integra de uma forma ou de outra, as três populações investigadas. Populações que se caracterizam por sua heterogeneidade interna, o que deu lugar à existência de fronteiras culturais e culturas de fronteira, tão significativas como as fronteiras político-administrativas.

O deslocamento das populações indígenas que ocorreu no passado, se traduz em novas formas de aproveitamento do meio, a chegada de novos contingentes populacionais, não só leva a supor um aumento da pressão sobre o meio, mas também significará uma forma diferente de conceituar o mesmo, com todos os problemas ambientais que ele pode gerar (Kay, 1996). A modificação das relações sociais implica, necessariamente, uma modificação do sistema ambiental.

Os referentes locais de identificação são centrais na interação cotidiana. Esta primazia permite aos habitantes da fronteira diferenciar entre "bolivianos", "peruanos", "brasileiros" e "bolivianos da fronteira", "peruanos da fronteira" e "brasileiros da fronteira". Este fato foi constatado nas diversas entrevistas realizadas. $\mathrm{O}$ recente conflito entre a Bolívia evidencia esta primazia do âmbito local de interação. Representantes políticos de Assis Brasil, por exemplo, fazem claramente a distinção entre as políticas do Estado central boliviano e dos habitantes da fronteira: "nossas relações não são influenciadas por estes fatos”. Não aconteceu assim com a fronteira da qual nos ocupamos, porém alguns representantes de Bolpebra manifestaram sua preocupação com as formas de ação de seu governo.

Esta diferenciação, entre os referentes estatais e locais aparece também nas imagens de identificação que existem entre os habitantes de umas e outras zonas. Em algumas entrevistas realizadas em Iñapari, aparece uma visão negativa “dos bolivianos": 
são traidores, pouco confiáveis e que se contrapõe com alguns aspectos positivos: "son buenos trabajadores".

Porém, esta visão é matizada quando nos referimos aos habitantes de Bolpebra: "ellos son buenas personas". Este tipo de afirmação evidencia que as imagens estatais não conseguiram diluir os referentes centrais, os referentes locais, na interação cotidiana. É certo que se produz uma tendência à homogeneização "do outro" em função do tempo que se viveu ou se vive na fronteira. Na medida em que as relações interfronteiriças se diluem e se desarticula o sistema de "área fronteiriça", as imagens tendem a homogeneizar-se, e os referentes locais passam para um secundo plano. Neste sentido, é interessante observar as claras diferenciações internas que foram geradas nas distintas localidades, em função das progressivas ondas de habitantes que chegaram a esta zona. Comecemos pelo Brasil.

Alguns estudos realizados colocam claramente em evidência as fronteiras simbólicas geradas entre os primeiros povos indígenas que chegaram a esta zona e que viviam da seringa e os colonizadores procedentes do Centro-Sul (Cardia, 2004). Ambos os grupos representavam duas formas de entender as relações com o meio e, portanto, as relações sociais. A chegada dos colonizadores supôs uma mudança fundamental no sistema socioeconômico, o que se traduziu em conflitos marcados. Como já assinalamos em outros trabalhos, em um mesmo espaço podem convergir diversos territórios, ou seja, diferentes formas de apropriação territorial. Uma clara fronteira simbólica dividiu durante muito tempo estes grupos, algo que se evidencia em todo o Acre e, de acordo com alguns testemunhos colhidos, também ficou evidente em alguns conflitos pontuais, no caso de Assis Brasil.

\section{Considerações Finais}

Atualmente as diferenças entre grupos na zona fronteiriça, pelo menos aparentemente, está diluída. O Estado brasileiro que, em grande parte gerou o conflito, contribuiu também para a sua dissolução, a partir do desenvolvimento do Estado do Acre que aceita, por um lado, a expansão das fazendas, enquanto reivindica como referente de identificação o "desenvolvimento sustentável", uma forma de articular 
discursos; mas também a grupos diferentes que hoje convivem em uma sociedade como a acreana, que passa por um claro processo de reafirmação identitária.

No caso de Bolpebra, as diferenças se estabelecem entre aqueles que chegaram na primeira colonização e em outras posteriores, vinculados por relações de parentesco e amizade, e outros grupos procedentes de outros locais. Sem dúvida, as pequenas dimensões desta localidade impedem, no momento, a articulação de grupos diferenciados. Especialmente interessante é o caso da região de Madre de Dios no Peru. Desde Puerto Maldonado até Iñapari, os peruanos marcam uma clara diferenciação entre os "serranos" e os "amazônicos", dois grupos que se percebem de forma antagônica e que nos podem esclarecer algumas das consequiências que podem ter a rodovia, do ponto de vista social e cultural.

A região amazônica peruana é escassamente povoada e continua recebendo população de outras partes do Peru. Este fenômeno, segundo informações colhidas em Puerto Maldonado, vem se acelerando nos últimos anos. São centenas de pessoas que chegam todos os dias a esta zona para buscar novas formas de viver, um fato que vem se acentuando a partir do anúncio da construção da Rodovia Transoceânica. Com isto, podemos falar do primeiro impacto antes, inclusive, de sua construção. Os novos habitantes vêm das regiões serranas. Algumas regiões, como Cuzco, estariam enviando um grande contingente populacional, em função das épocas de crise no campo. Os serranos que chegaram massivamente se percebem e são percebidos de uma forma distinta dos amazônicos que, em alguns casos, antepõem sua nacionalidade, preferindo manter relações sociais com outros amazônicos, os brasileiros. De fato, a presença de brasileiros nesta cidade vem sendo muito importante e, provavelmente, com a construção da estrada, volte a sê-lo. Vejamos quais são as imagens que conformam à fronteira simbólica entre "serranos" e "amazônicos".

Os serranos gostam muito das festas dos amazônicos. Estes são considerados sem nenhuma projeção de futuro, incapazes de ter uma visão em longo prazo, o que faz deles pessoas sem ambição alguma. Não gostam de trabalhar e o que ganham gastam rapidamente. Estão especialmente preocupados com a aparência, cuidam muito do seu aspecto e sua roupa, especialmente para a diversão. As mulheres amazônicas são mais promíscuas e de pouca confiança, dedicam pouco tempo aos trabalhos domésticos e aos trabalhos próprios das mulheres. Os amazônicos vivem, portanto, com o que a floresta 
lhes oferece e não se preocupam em ascender econômica e socialmente. Circulam bem por um espaço que é considerado por boa parte dos serranos como ameaçador e perigoso: a floresta.

As imagens que definem o "outro", servem também para auto-definição, ou seja, os serranos aceitariam algumas das qualificações com as quais são definidos, ainda que tenham outra leitura. Igualmente como acontece com os amazônicos. O trabalho é visto como um valor fundamental para os serranos e, neste sentido eles são "muy trabajadores"; enquanto que, para os amazônidas o trabalho é visto como um fim que permite alcançar outros tipos de coisas.

Como vemos as fronteiras entre as distintas populações se fazem evidentes, na medida em que outros grupos procedentes do mesmo país chegam à Amazônia. Este fenômeno é indicativo da progressiva mudança populacional que está se produzindo e que está afetando diversos planos da vida social e cultural, e também a importância da fronteira como referente de identificação.

Para os novos moradores, a legitimação a partir da qual se justifica sua chegada, tem a ver com o fato de pertencerem ao mesmo país. O ser peruano dá o mesmo direito de usar parte do território nacional. A fronteira adquire, assim, um novo valor como referente fundamental de identificação, a partir da qual se unifica os que estão mais distantes do limite político-administrativo marcado pelo próprio Estado. Se as fronteiras entre velhos moradores e novos moradores são realmente marcadas, mais ainda o são as fronteiras que se estabelecem com os "estrangeiros". Afinal, os habitantes que vivem há mais tempo na fronteira, conhecem os outros, seus vizinhos. Os novos moradores chegam com outras normas, outras formas de compreender as relações com o entorno e, claro, com outra forma de justificar o direito a um mesmo espaço territorializado de maneira diferente.

En” el pueblo" "3 la gente es de fuera, no hay uno de aquí (¿se nota la diferencia entre la gente de fuera y la de aquí?) Sí, no se con que idea vienen ellos... aquí nosotros somos más humanos, nos ayudamos más entre nosotros. Dona de casa, habitante do bairro Colônia (Iñapari).

\footnotetext{
${ }^{3} \mathrm{O}$ "povoado" é contraposto à "colônia", um dos bairros de Iñapari onde, segundo esta informante, seria maior a presença de pessoas "de aquí".
} 
A fronteira não é só uma realidade espacial, mas é também uma representação que se ativa nos diferentes grupos sociais. É por isso que a chegada de novos contingentes populacionais supõe a reafirmação da fronteira, tanto que a visão dos estrangeiros está forjada por imagens transmitidas a partir de diferentes instâncias, incluídos os aparatos do Estado. Porém, não é pela interação cotidiana que surge uma série de interesses complementares entre populações. Não é estranho, portanto, que as imagens das populações "recentes", independentemente do país a que nos referimos, com relação à fronteira perdem em riquezas de matizes, em relação àqueles grupos que vivem a mais tempo no local.

\section{Referências bibliográficas}

AUGÉ, Marc. 1993. Los “no lugares”. Espacios del anonimato. Barcelona: Gedisa.

BARTH, Fredrik. 1976. Los grupos étnicos y sus fronteras. México: F.C.E.

BARBOSA, Cleto B. 2003. Diversidade vegetal em florestas do estado do Acre: aplicação de modelos ecológicos e do conhecimento tradicional. Tese (Doutorado) Florianópolis: PPGG/UFSC.

CARDIA, Laís M. 2004. “Meu Lugar Agora é Aquî". Trajetórias e memórias de colonos e seringueiros para Rio Branco, Acre - Uma abordagem antropológica. Florianópolis: PPGAS/UFSC.

CUCHE, Denys. 1999. A noção de cultura nas Ciências Sociais. Bauru: EDUSC.

ESCALERA, Javier 1999. Territorios, limites, fronteras: construcción social del espacio y identificaciones colectivas. In MUÑOZ, J. Pujadas \& DÍAS, Emma (org). Globalización, fronteras culturales y políticas y ciudadanías. Actas del VIII Congreso de Antropología. Asociación Galega de Antropología.

GARCIA, J. Luis. 1976. Antropología del territorio. Madrid: Taller de Ediciones Josefina Betancor.

GODELIER, Maurice. 1984. L'ideel et le material. Paris: ED. Fayar. 
HERRERO, M. 1994. Partido y Frontera. In Revista de Antropología Social 3. (org). Carmelo Lisson. Editora: Univerdidad Complutense de Madrid.

MACHADO, L. 1996. Paisagem valorizada: a Serra do Mar como espaço e lugar. São Paulo: Studio Nobel.

KAY, Milton. 1996. Ecologías: antropología, cultura y entorno. Consulta realizada no site

http://www.unesco.org/issj/rics154/miltonspa.html.10/01/2009.

PÁLSON, Gísli \& DESCOLA, Philippe (org). 2001. Naturaleza y sociedad: perspectivas antropológicas. México: Siglo Veintiuno Editores.

PAUL-LÉVY, F. \& SEGAUD, M. 1983. Antropologie de l'espace. Paris: Centre George Pompidou.

PESAVENTO, Sandra. 2003. Além das fronteiras. In MARTINS, M. Helena (org). Fronteiras Culturais. Porto Alegre: Secretaria Municipal de Cultura/Ateliê Editorial. Pp. 35-39.

URIARTE, Luis. 1994. La codosera: culturas de frontera e frontera culturales. Mérida: Asablea de Extremadura.

VALCUENDE, José Ma $\mathrm{M}^{\mathrm{a}}$ 1998. Fronteras, territórios e identificaciones colectivas. Sevilla: Fundación Blas Infante.

VALCUENDE, José $\mathrm{M}^{\mathrm{a}}$. 1999. Espacio, território y comunidade: procesos de identificación y discursos. In MUÑOZ, Juan Pujadas et al (org). Globalización, fronteras culturales y políticas y ciudadanía. Actas del VIII Congreso de Antropología. Asociación Galega de Antropología, pp. 217-227.

VALVA, Milena D’Ayale. 2001. Reflexões sobre espaço, lugar e paisagem. In Estudos, vol. $28, n^{\circ} 1$, pp. 55-66. 
Recebido para publicação em junho de 2009 Aprovado para publicação em agosto de 2009 